\title{
SISTEM TANYA JAWAB MENGGUNAKAN WEB SERVICES
}

\author{
Supriyono \\ Jurusan Teknik Informatika, Sains dan Teknologi \\ Universitas Islam Negeri (UIN) Maulana Malik Ibrahim Malang \\ supriyono.uin@gmail.com
}

\begin{abstract}
Abstrak- Sistem tanya jawab mampu meningkatkan kualitas dan keefektifitasan akuisisi pengetahuan pada sebuah web. Pencarian data pada suatu web menyediakan sekumpulan dokumen yang sesuai dengan kata kunci yang dimasukkan oleh pengguna. Pengguna perlu mempelajari lebih lanjut dokumen-dokumen tersebut untuk mendapatkan pengetahuan yang diinginkan pengguna. Sistem Tanya Jawab dibangun dengan menyediakan sebuah knowledge. Penelitian berikut ini menyajikan framework untuk membangun sistem tanya jawab menggunakan teknologi web services. Dalam framework berikut ini, pertanyaan yang inputkan kedalam sistem dengan menggunakan natural language yang diterjemahkan ke dalam struktur semantik yang dilakukan untuk mengekstrak pengetahuan untuk menjawab pertanyaan-pertanyaan. Media pengetahuan merumuskan jawaban yang diperlukan oleh sistem. Sumber knowledge dapat secara dinamis diperluas, ditemukan, dan dimediasi untuk sistem tanya jawab. Hasil yang diperoleh yaitu dengan pendekatan skenario sistem tanya jawab dengan contoh inputan query.
\end{abstract}

Kata kunci : framework, knowledge, semantic, natural language.

\section{PENDAHULUAN}

ISTEM tanya jawab merupakan suatu Spermasalahan utama dalam pembahasan natural language processing. Suatu basis pengetahuan sistem dapat dibangun untuk keperluan berbagai macam kebutuhan. Diantaranya adalah kebutuhan untuk pencarian informasi pada suatu web agar relevan dengan kata yang diinputkan oleh pengguna. Peningkatan sistem tanya jawab fokus pada 3 area yaitu content yang terdiri dari informasi repositori dokumen web, query, dan jawaban. Sistem tanya jawab yang dibangun lebih mudah digunakan, cepat dan tepat daripada mesin pencarian sederhana. Sistem tanya jawab terdiri dari tiga proses diantaranya adalah memahami pertanyaan dari pengguna, information retrieval dan ekstraksi jawaban. Perkembangan sistem tanya jawab yang populer adalah menggunakan teknologi web services didalam pengolahan data.

Web services merupakan teknologi terkini untuk mengintegrasikan program lain yang berbeda platform. XML Web Services menyimpan data dalam format XML yang menjadikannya multiplatform dalam hal aksesibilitasnya. Web Services menyediakan fungsi-fungsi yang dapat digunakan ulang dari perangkat lunak yang lainnya. Web Services Description Language (WSDL) merupakan sebuah bahasa berbasis XML yang digunakan untuk menggambarkan fungsi-fungsi dari web service. Cara untuk melakukan query dari sebuah data dapat menggunakan SPARQL yang mana merupakan bagian dari rekomendasi W3C untuk melakukan query pada dokumen dengan format RDF/OWL.

Tujuan dari penelitian berikut ini adalah membangun kerangka kerja pada sistem tanya jawab dengan menggunakan web services. Basis pengetahuan yang dibangun untuk merancang sistem tanya jawab dapat diimplementasikan dalam aplikasi web menggunakan Ontology Web Language sebagai bagian dari teknologi Semantic Web menggunakan Java Sever Pages, Jena, Protégé dan bahasa query SPARQL.

\section{TINJAUAN PUSTAKA}

\subsection{Sistem Tanya Jawab}

Kebutuhan sistem yang ada hubungannya dengan pencarian informasi adalah mencari jawaban yang tepat untuk kebutuhan informasi yang bersifat spesifik dari sebuah dokumen yang kompleks. Hal tersebut dikenal sebagai sistem tanya jawab. Mekanisme dari sistem tanya jawab adalah dengan melakukan ekstraksi jawaban kemudian dilanjutkan dengan pencarian dokumen, sehingga potongan teks yang ditanyakan terdapat kesamaan yang bertujuan untuk digunakan menjawab pertanyaan.

Teknologi sistem tanya jawab menerapkan ekstraksi suatu pertanyaan yang digunakan untuk mencari jawaban yang sesuai. Hasil ekstraksi pertanyaan bertujuan untuk menemukan pola dalam sistem. Secara umum sistem tanya jawab terdiri dari empat modul yaitu analisa dari proses pertanyaan, perbaikan dokumen 


\subsection{Service-Oriented Architecture (SOA)}

Service oriented architecture merupakan sebuah metode business-driven untuk perancangan teknologi informasi yang lumayan rumit. Proses integrasi proses bisnis yang bervariasi memerlukan sebuah teknologi yang dapat menjembatani hal itu semuanya. W3C mendefinisikan 3 aturan dalam SOA yaitu service provider, service consumer, dan service broker. Web service merupakan bentuk implementasi SOA yang dapat memberikan kemudahan dalam membangun sistem tanya jawab.

Web services yang dibangun memungkinkan sebuah aplikasi dapat berkomunikasi dan menyediakan layanan bagi aplikasi lain serta memberikan kemudahan upaya integrasi antarsistem yang berbeda platform. Sebuah aplikasi berbasis teknologi Web service dapat menyediakan data maupun fungsi tertentu bagi aplikasi lain walaupun berbeda pengembangan perangkat lunaknya.

\section{METODOLOGI PENELITIAN}

Metodologi penelitian merupakan langkahlangkah yang dilakukan dalam penelitian. Penelitian berikut ini terdiri dari beberapa tahapan proses yang dilakukan mulai dari studi literatur, analisis kebutuhan, perancangan skenario, perancangan sistem, dan analisis hasil. Langkahlangkah yang dilakukan dalam penelitian terdapat pada Gambar 1.

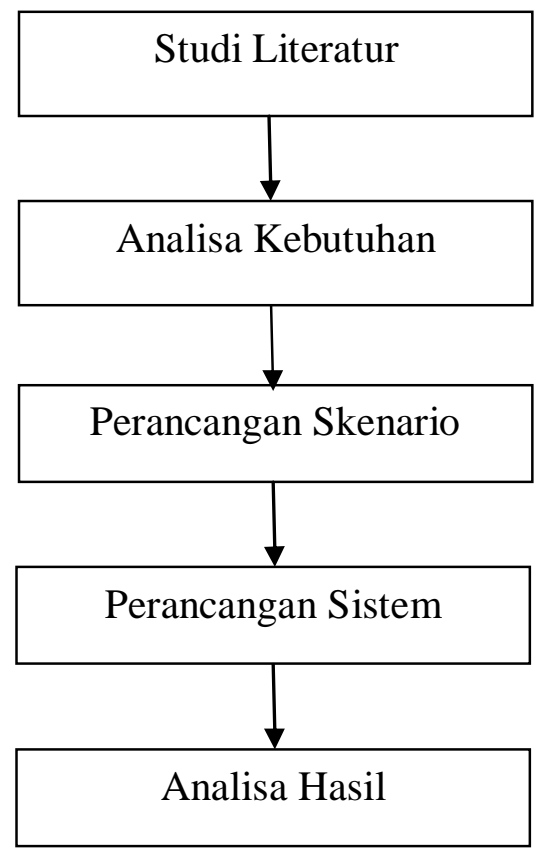

Gambar 1. Tahapan Proses Penelitian

\subsection{Analisa Kebutuhan}

Pada bagian ini mengidentifikasi kebutuhan yang berkaitan dengan pengujian model dan teori yang dapat dibuktikan kebenarannya secara ilmiah. Identifikasi kebutuhan penelitian yang dilakukan bertujuan agar penelitian dapat lebih fokus dalam penyelesaian permasalahan. Hasil identifikasi kebutuhan yang diperoleh terdiri dari pertanyaan yang diinputkan disistem, pengolahan pertanyaan yang diinputkan dengan melakukan ekstraksi data dan rancangan web service untuk menjembatani sistem tanya jawab.

\subsection{Perancangan Skenario}

Pada bagian berikut ini bertujuan untuk mempermudah sistem yang dibuat dengan cara membuat alur secara sistematis, efektif dan efisien. Manfaat yang diperoleh pada perancangan skenario yang dilakukan pada penelitian berikut ini adalah seperti pada gambar 2 berikut ini.

Pada gambar skenario Gambar 2 menunjukkan bahwa pengguna sistem memasukkan pertanyaan pada sistem tanya jawab. Pertanyaan tersebut terdiri dari beberapa kata kunci yang kemudian dilakukan pemrosesan sehingga dihasilkan jawaban yang sesuai dengan pertanyaan tersebut.

\subsection{Perancangan Sistem}

Bagian ini bertujuan untuk mengetahui model system tanya jawab secara menyeluruh beserta gambaran implementasi secara umum. Pada perancangan sistem tanya jawab yang diusulkan penelitian berikut ini adalah seperti pada gambar 3 .

$$
\text { Rancangan arsitektur sistem yang }
$$
diusulkan dalam membangun sistem tanya jawab yang menghubungkan pengguna sistem dan pengintegrasian sistem tanya jawab adalah seperti pada gambar 4 . 


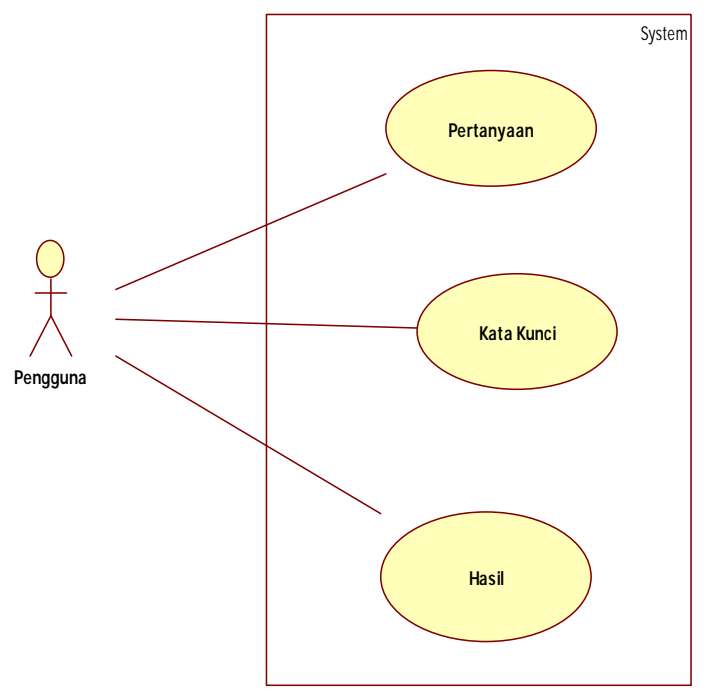

Gambar 2. Perancangan Skenario Sistem

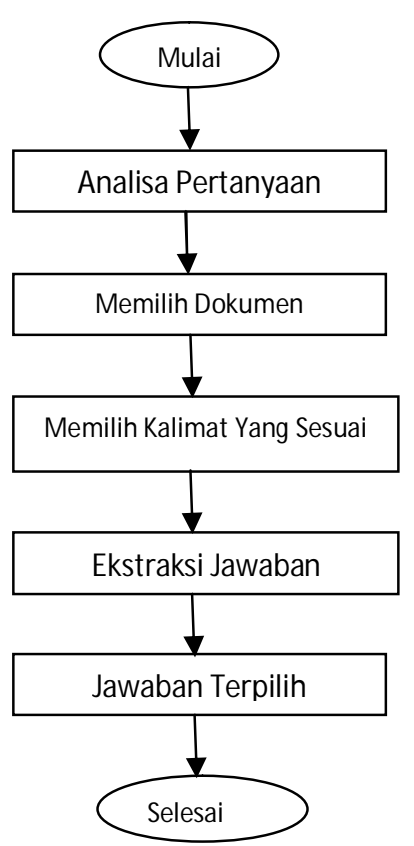

Gambar 3. Perancangan Sistem

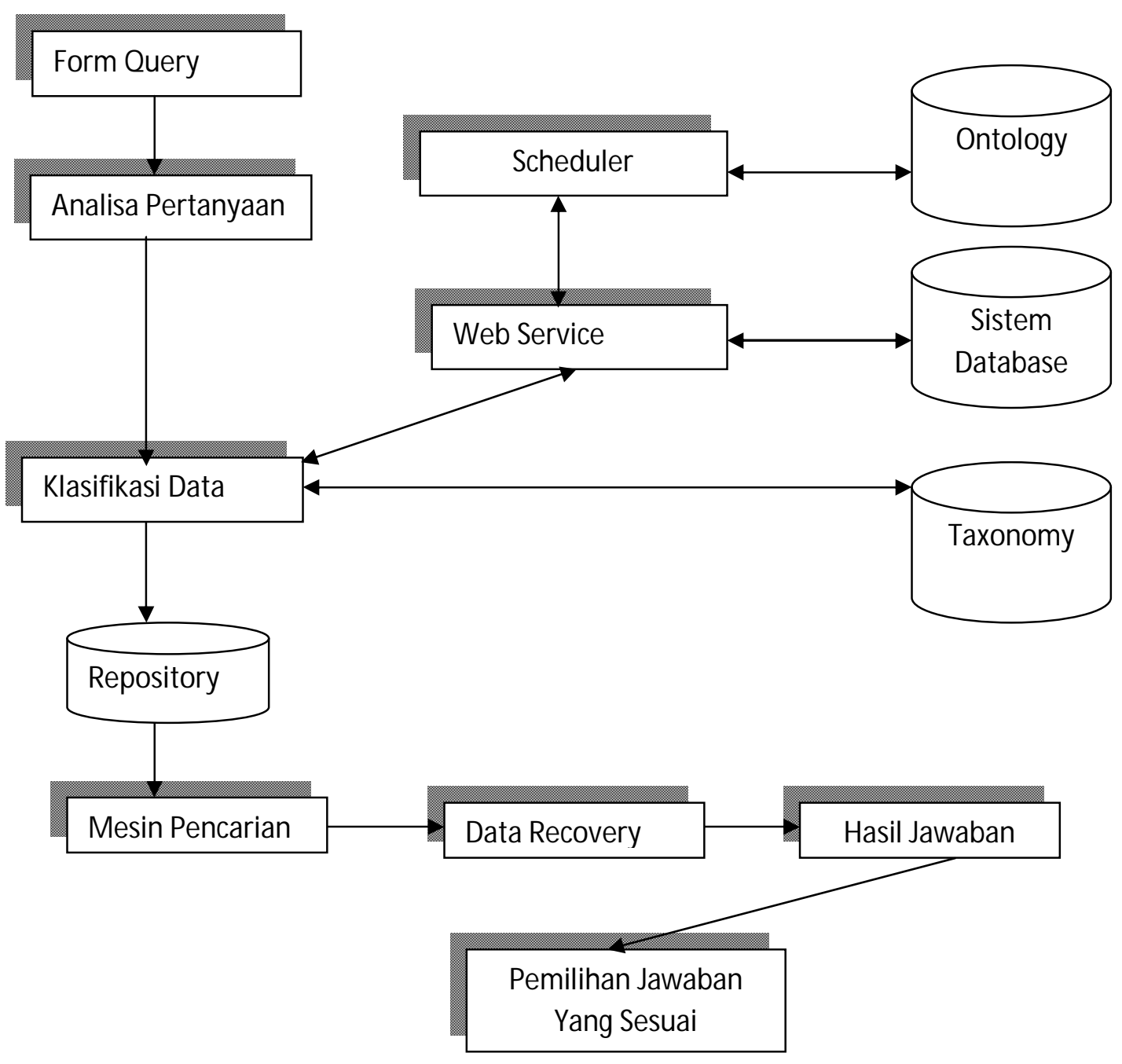

Gambar 4. Gambar Arsitektur Integrasi Sistem Tanya Jawab 


\section{HASIL DAN PEMBAHASAN}

Rancangan sistem tanya jawab yang diusulkan adalah dengan melakukan integrasi sistem dengan teknologi web services. Pada bagian form query digunakan untuk melakukan pengoperasian antara pengguna dengan sistem. Hasil inputan dari pengguna sistem dilakukan analisa pertanyaan dan melakukan klasifikasi data dari pertanyaan yang sudah dimasukkan ke dalam sistem. Data Pertanyaan dari pengguna yang sudah terklasifikasi dilakukan pemprosesan dengan menggunakan teknologi web service sebagai pengubung untuk pengintegrasian sistem.

Pada bagian scheduler berkaitan dengan proses interaksi dengan berbagai komponen untuk menentukan jenis pertanyaan, tingkat respon yang diharapkan dan fokus pertanyaan. Tujuan dari bagian ini adalah untuk struktur query yang sifatnya logis dengan menggunakan klasifikasi data yang sudah diinputkan.

OWL biasa digunakan untuk merancang ontology yang berisi beberapa informasi yang pada dasarnya adalah berkaitan dengan struktur informasi formal. Informasi yang diperoleh didasarkan dari data yang disimpan dalam sebuah sistem database yang menggambarkan suatu basis pengetahuan.

Hasil dari beberapa tahapan untuk menentukan klasifikasi data yang sudah siap untuk diolah pada sistem tanya jawab dilakukan penyimpanan sementara kedalam repository. Setelah proses tersebut dilakukan selanjutnya adalah diproses pada mesin pencarian serta melakukan perbaikan sehingga dihasilkan jawaban yang tepat.

\section{KESIMPULAN DAN SARAN}

Penelitian berikut ini menghasilkan sebuah kerangka kerja yang digunakan untuk mengembangkan sistem tanya jawab dengan menggunaan teknologi web services yang digunakan untuk menjembatani pemrosesan data. Penelitian berikut ini dapat dikembangkan lagi dengan menerapkan penggabungan semantic web dan web services supaya dapat dihasilkan suatu kerangka kerja yang lebih efektif. Selain itu dapat menggunakan data uji dari sistem yang kompleks.

\section{DAFTAR PUSTAKA}

[1] Jang Minsu, Sohn Joo-Chan, Cho Hyun Kyu.2007.Automated Question Answering using Semantic Web Services. IEEE AsiaPacific Services Computing Conference

[2] L. McGuinness, Deborah. 2004. Question Answering on the Semantic Web. Stanford University.

[3] Liu Yang, Hu Enzhao, Chen Xudong. 2010. Architecture of Information System Combining SOA and BPM. 2nd International Conference on Software Technology and Engineering(ICSTE)

[4] Ong Chorng-Shyong, Day Min-Yuh, Hsu Wen-Lian. 2008. Development of an Evaluation Model for Question Answering Systems. IEEE IRI. Las Vegas, Nevada, USA

[5] Sucunuta Manuel E, Riofrio Guido E. 2010. Architecture of a Question-Answering System for a Specific Repository of Documents. 2nd International Conference on Software Technology and Engineering(ICSTE)

[6] Wei Zhang, Xuan Zhang. 2012. Design and Implementation of Influenza Question Answering System Based on Multistrategies. IEEE 